\title{
Effect of Lecithin Coating on the Pulmonary Absorption of Furosemide in Rats
}

\author{
Yuko SAso, ${ }^{a, b}$ Toshinobu Seki,${ }^{a}$ Rie FukUChI,${ }^{a}$ Sumio Chono,,${ }^{a}$ and Kazuhiro Morimoto ${ }^{*, a}$ \\ ${ }^{a}$ Hokkaido Pharmaceutical University School of Pharmacy; 7-1 Katsuraoka-cho, Otaru, Hokkaido 047-0264, Japan: and \\ ${ }^{b}$ Clinical Development, Scientific Affairs, Sanofi-Aventis K.K.; 3-20-2 Nishishinnjiku, Tokyo 163-1488, Japan. \\ Received January 27, 2006; accepted April 19, 2006
}

\begin{abstract}
The effect of lecithin coating on the pulmonary absorption of furosemide after application by metered dose inhalers (MDI) containing HFA 227 was evaluated in rats. The plasma concentration of furosemide after application of lecithin-coated furosemide was higher than that after application of the un-coated form. Since the disposition in the lung $2 \mathrm{~min}$ after application of un-coated furosemide was significantly lower than that after application of the coated form and the adsorption to a polyethylene tube used for the application of the un-coated form was significantly higher than that of the coated form, the higher plasma concentration after application of lecithin-coated furosemide could be partly related to the efficient delivery of the furosemide particles to the lung. The permeation-enhancing effect of the lecithin coating was investigated using Calu-3 cell monolayers. The cumulative amount of furosemide permeated over $2 \mathrm{~h}$ from a suspension containing lecithin-coated furosemide through the monolayers was significantly higher than that from a conventional furosemide suspension. This enhancing effect could also contribute to the high plasma concentration of furosemide in rats. The lecithin-coated furosemide will be useful for the formulation of MDI offering high bioavailability.
\end{abstract}

Key words pulmonary absorption; furosemide; metered dose inhaler; lecithin; rat

Metered dose inhalers (MDI) containing chlorofluorocarbons (CFCs) have been used for the delivery of therapeutic agents to the respiratory tract to treat asthma and related diseases. However, the pharmaceutical companies have had to replace the ozone-depleting CFCs by hydrofluoroalkanes (HFAs) propellants because of the phasing out of the former. ${ }^{1,2}$ Since HFAs differ from CFCs in their density, polarity and vapor pressure, formulation studies are needed to develop MDI containing HFAs. ${ }^{3-5)}$ Surfactants act as dispersing agents and also ensure suspension stabilization, control of crystal growth and lubrication of the metered valve in the suspension MDI formulations. ${ }^{6-8)}$ However, most of the surfactants, such as oleic acid, lecithin, and sorbitan trioleate, are insoluble in HFAs. ${ }^{9)}$ Since surfactants stabilize the suspension and lubricate the metered valve, processes such as coating active drug particles with lecithin are used for formulations of MDI. ${ }^{10,11)}$ The lecithin-coated particles exhibit low cohesivity and act as a lubricant to avoid clogging the inhaler valve. ${ }^{12)}$

In our previous study, lecithin-coated furosemide was prepared and used for formulation of an MDI with HFA 227. ${ }^{13)}$ The dosing reproducibility of the MDI containing lecithincoated furosemide was better than that of one containing uncoated furosemide, suggesting that lecithin-coating is useful for formulations of MDI. ${ }^{13,14}$ Since lecithin enhances the mucosal absorption of some drugs, the lecithin coating could help improve the bioavailability after dosing using the MDI. ${ }^{15,16)}$

In the present study, the effect of the lecithin coating on the pulmonary absorption of furosemide after application by an MDI containing HFA 227 was evaluated in rats. In addition, the permeation-enhancing effect of lecithin was investigated using Calu-3 cell monolayers. ${ }^{17-20)}$

\section{MATERIALS AND METHODS}

Materials $\mathrm{HFA} 227\left(\mathrm{CF}_{3} \mathrm{CHFCF}_{3}\right.$; molecular weight,
170.03; boiling point $\left({ }^{\circ} \mathrm{C}\right),-16.8$, specific gravity $(\mathrm{kg} / \mathrm{l}$, $20^{\circ} \mathrm{C}$ ), 1.412) was provided by Solvay (Hannover, Germany). Lecithin (soybean, LIPOID S 100) was kindly supplied by Lipoid GmbH (Germany). Furosemide (JP-XIV) was obtained commercially and used as uncoated furosemide or to prepare lecithin-coated furosemide. All other chemicals were of reagent grade and used as received.

Preparation of Lecithin-Coated Furosemide The lecithin-coated furosemide was prepared as described previously. ${ }^{13)}$ Briefly, the lecithin $(0.40 \mathrm{~g})$ dispersed in $80 \mathrm{ml}$ distilled water was kept at room temperature for $1 \mathrm{~d}$ and then furosemide $(20 \mathrm{~g})$ was dispersed in it by sonicating for $1 \mathrm{~min}$ (SU-18TH, Shibata Science, Tokyo, Japan). The resulting suspension was freeze-dried to obtain lecithin-coated furosemide. The content of furosemide in the lecithin-coated furosemide $(98.0 \%)$ agreed with that calculated from the amounts of furosemide and lecithin used for the preparation. ${ }^{13)}$ The lecithin coating did not affect the appearance under SEM examination, but the results of X-ray photoelectron spectroscopy analysis, demonstrating the presence of phosphorus from lecithin on the surface of the particles, confirms the coating of lecithin on the surface of the furosemide powder. ${ }^{13)}$ The diameters of the scattered particles of the untreated furosemide and lecithin-coated furosemide under dry conditions were $1.55 \mu \mathrm{m}$ ( $10 \%$ diameter $-90 \%$ diameter; $0.69-3.01 \mu \mathrm{m})$ and $1.78 \mu \mathrm{m}(0.81-3.08 \mu \mathrm{m})$, respectively, suggesting that the coating did not cause any aggregation. ${ }^{13)}$

Dissolution profiles of furosemide and lecithin-coated furosemide were evaluated in PBS (pH 7.4). Furosemide or lecithin-coated furosemide $50 \mathrm{mg}$ was dispersed in PBS $10 \mathrm{ml}$ at $37^{\circ} \mathrm{C}$. At predetermined times, $500 \mu \mathrm{l}$ of each suspension was withdrawn and then filtered through a membrane $(0.45 \mu \mathrm{m}$, HLC-DISK 13 , KANTO CHEMICAL, Tokyo, Japan). The concentration of furosemide in the filtered solution was determined by HPLC analysis.

The HPLC system (Shimadzu, Kyoto, Japan) consisted of a pump (LC-9A), detector (SPD-10A) and integrator (CR- 
6A). An analytical column (Inertsil ODS $5 \mu \mathrm{m}, 250 \times 4.6 \mathrm{~mm}$ i.d.; GL Science, Tokyo, Japan) and a mobile phase $(50 \mathrm{~mm}$ $\mathrm{KH}_{2} \mathrm{PO}_{4}$ : acetonitrile $=68: 32$ ) were used for the separation. The flow-rate was $0.8 \mathrm{ml} / \mathrm{min}$ and the detector was operated at $273 \mathrm{~nm}$.

Preparation of MDI A valve (DF10/25ATC), designed to release $35 \mathrm{mg}$ HFA 227 by one actuation, was kindly supplied by Valois (France). Furosemide or lecithin-coated furosemide corresponding to furosemide $500 \mathrm{mg}$ was added to each aluminum aerosol can $(28 \mathrm{ml}, \mathrm{C} 326$, Presspart, England) and then sufficient HFA227 propellant was added by pressure filling after crimping the valves according to the manufacturer's recommended specifications for the cans. The total weight of the contents was $14.0 \mathrm{~g}$.

Animal Studies Animal experiments were carried out in accordance with the Guiding Principles for the Care and Use of Experimental Animals, Hokkaido Pharmaceutical University School of Pharmacy (2005). Male Sprague-Dawley rats, 7 weeks of age, were fasted for $18-20 \mathrm{~h}$ prior to the experiment. Intratracheal administration was carried out according to the method of Enna and Schanker. ${ }^{21,22)}$ The rats were anesthetized with urethane and held in the supine position on a plate kept at $37^{\circ} \mathrm{C}$. The trachea was exposed and a polyethylene tube (outer diameter $2.33 \mathrm{~mm}$, inner diameter $1.3 \mathrm{~mm}$, length $80.0 \mathrm{~mm}$ ) was inserted through the site of the tracheal incision. A stainless steel nozzle (outer diameter $1.0 \mathrm{~mm}$ ) attached to the valve of the MDI was inserted into the polyethylene tube and then a dose was administered by a single actuation. The dose was $1.25 \mathrm{mg}$ furosemide/body theoretically. Blood samples were collected from the tail vein at 5, 15, 30, $60,120,240$ and $360 \mathrm{~min}$ after administration. The plasma $(100 \mu \mathrm{l})$ was mixed with $1 \mathrm{M} \mathrm{KH}_{2} \mathrm{PO}_{4}(500 \mu \mathrm{l})$ and then the furosemide was extracted using diethyl ether. The diethyl ether phase was dried under $\mathrm{N}_{2}$ gas and then the residue was dissolved in mobile phase $(250 \mu \mathrm{l})$. The concentration of furosemide in the solution was determined by HPLC. Apparent first order elimination rate constants for terminal phase of plasma concentration-time curves were calculated by regression analysis and were used to obtain the values of the biological half-lifes $\left(t_{1 / 2}\right)$ and the area under the curves from $0 \mathrm{~h}$ to $\infty(A U C)$.

In order to evaluate the disposition of furosemide in the lung and adsorption to the polyethylene tube, intratracheal administration was carried out separately. ${ }^{23}$ The lung was excised 2 min after administration and then the furosemide was extracted from the lung using diethyl ether. The inside of the polyethylene tube used for dosing was washed with methanol $(50 \mathrm{ml})$ and the concentrations of furosemide in the resulting solutions were determined by HPLC.

In Vitro Permeation through Calu-3 Cell Monolayers Calu-3 cells were obtained from ATCC (Manassas, VA, U.S.A.). The cells were maintained in DMEM F-12 HAM (Sigma, St. Louis, MA, U.S.A.) containing 10\% heat-inactivated fetal calf serum, $40 \mu \mathrm{g} / \mathrm{ml}$ gentamicin and $1 \%$ nonessential amino acids, in a humidified atmosphere of $95 \%$ air and $5 \% \mathrm{CO}_{2}$ at $37^{\circ} \mathrm{C}$. Cells from passage number $39-47$ were seeded $\left(4.5 \times 10^{5} \mathrm{cell} / \mathrm{cm}^{2}\right)$ on polyester filter inserts (pore size $0.4 \mu \mathrm{m}$, area $0.33 \mathrm{~cm}^{2}$, Transwell, Costar) for the drug permeation experiments. The medium in the apical compartment was removed one day after seeding to allow the monolayer to grow at the air-interface and then the cells were

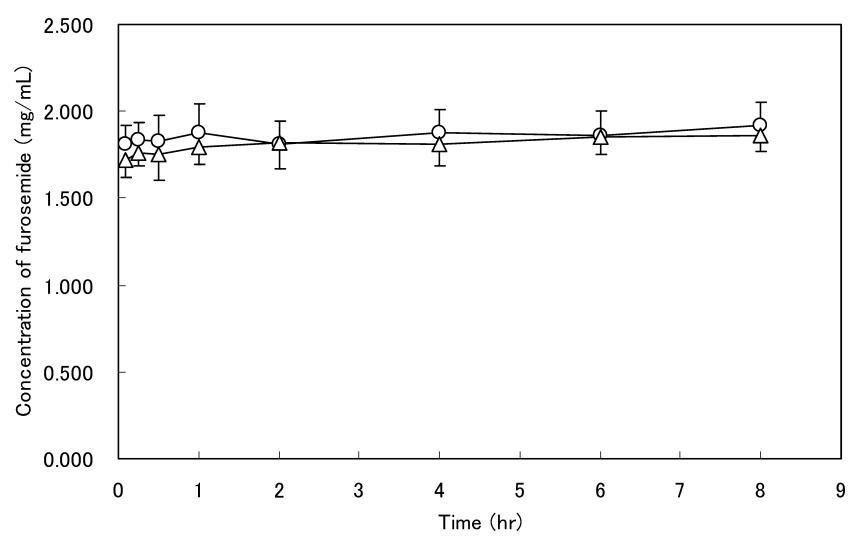

Fig. 1. Dissolution Profiles of Furosemide (Un-coated) and LecithinCoated Furosemide in PBS

Furosemide or lecithin-coated furosemide was dispersed $(5.0 \mathrm{mg} / \mathrm{ml})$ in PBS at $37^{\circ} \mathrm{C}$. $\triangle$, furosemide; $\bigcirc$, lecithin-coated furosemide. Each data set is the mean \pm S.D. $(n=5)$

cultivated until confluent for $14-17 \mathrm{~d}$ before starting the transport experiments.

Furosemide or lecithin-coated furosemide was dispersed (10 mg furosemide equivalent $/ \mathrm{ml}$ ) in PBS and the suspension $(100 \mu \mathrm{l})$ was applied to the apical side. Hanks balanced salt solution (HBSS, pH 7.4, $0.60 \mathrm{ml}$ ) was used as the basolateral side solution. The HBSS was changed every $30 \mathrm{~min}$ for $2 \mathrm{~h}$. Transepithelial resistance (TER) was measured using Millicell $^{\circledR}$-ERS (Millipore, MA, U.S.A.) before and after the transport experiments. The concentration of furosemide in the basolateral solution was determined by HPLC.

Statistical Analysis The mean values and the standard deviation (S.D.) were calculated in each experiment. The statistical significance of each treatment was evaluated by Student's $t$-test or the Mann-Whitney $U$ test under consideration of the homoscedaticity of samples. StatView software (Ver. 5.0, SAS Institute Inc.) was used for the calculations.

\section{RESULTS}

Effect of Lecithin Coating on the Dissolution of Furosemide Since phospholipids act as solubilizers for some drugs, the effect of lecithin coating on the dissolution profiles of furosemide was tested first. ${ }^{24)}$ Figure 1 shows the dissolution profiles from un-coated and lecithin-coated furosemide in PBS at $37^{\circ} \mathrm{C}$. The dissolution of furosemide was rapid and the lecithin coating had no marked effects on the dissolution rate and solubility of furosemide.

Effect of Lecithin Coating on the Pulmonary Absorption of Furosemide The plasma concentrations of furosemide after intratracheal administration using MDI containing un-coated or lecithin-coated furosemide are shown in Fig. 2 and the pharmacokinetic parameters are shown in Table 1 . The maximum concentration $\left(C_{\max }\right)$ and area under the plasma concentration-time curve $(A U C)$ following use of the MDI containing lecithin-coated furosemide were significantly higher than those following use of the MDI containing un-coated furosemide. Since the lecithin coating could not change the elimination of furosemide, the difference between the two formulations in terms of the plasma concentration profiles will be related to the availability until absorption occurs. 


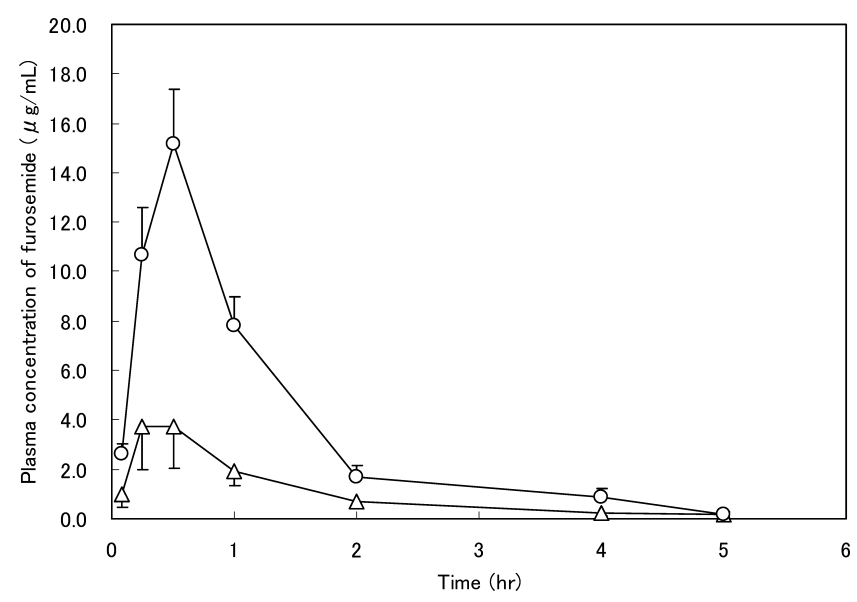

Fig. 2. Plasma Concentration of Furosemide after Intratracheal Adminis tration of Furosemide or Lecithin-Coated Furosemide Using MDI in Rats

Dose was $1.25 \mathrm{mg}$ furosemide/body. $\triangle$, furosemide; $\bigcirc$, lecithin-coated furosemide Each data set is the mean \pm S.D. $(n=5)$.

Table 1. Pharmacokinetic Parameters after Intratracheal Administration of Furosemide in Rats

\begin{tabular}{lccc}
\hline \hline & $C_{\max }(\mu \mathrm{g} / \mathrm{ml})$ & $t_{1 / 2}(\mathrm{~h})$ & $A U C(\mu \mathrm{g} \cdot \mathrm{h} / \mathrm{ml})$ \\
\hline Un-coated furosemide & $3.9 \pm 1.8$ & $1.37 \pm 0.57$ & $5.3 \pm 1.7$ \\
Lecithin-coated furosemide & $\left.15.2 \pm 2.2^{a}\right)$ & $0.95 \pm 0.23$ & $17.2 \pm 2.6^{a)}$
\end{tabular}

Each data set is the mean \pm S.D. $(n=5)$. a) Significant difference compared with uncoated furosemide in an unpaired Student's $t$-test $(p<0.0001)$.

Table 2. Disposition of Furosemide 2 min after Intratracheal Administration in Rats

\begin{tabular}{lcc}
\hline \hline & $\begin{array}{c}\text { Disposition in lung } \\
(\mathrm{mg})\end{array}$ & $\begin{array}{c}\text { Adsorption to } \\
\text { polyethylene tube (mg) }\end{array}$ \\
\hline Un-coated furosemide & $0.144 \pm 0.059$ & $0.291 \pm 0.091$ \\
Lecithin-coated furosemide & $0.380 \pm 0.068^{a)}$ & $0.152 \pm 0.009^{b)}$ \\
\hline
\end{tabular}

Each data set is the mean \pm S.D. $(n=3)$. a) Significant difference compared with uncoated furosemide in an unpaired Student's $t$-test $(p<0.05) . b)$ Significant difference compared with un-coated furosemide in the Mann-Whitney $U$ test $(p<0.05)$.

In order to investigate the factors associated with the reduction in availability, the disposition of furosemide in the lung and its adsorption to the polyethylene tube were evaluated. The amount of furosemide in lung $2 \mathrm{~min}$ after intratracheal administration using the MDI containing lecithincoated furosemide was significantly higher than that using the MDI containing un-coated furosemide (Table 2). On the other hand, the amount of furosemide adsorbed to the polyethylene tube was significantly higher in the case of the uncoated furosemide (Table 2). There was a marked difference in delivery to the lung between un-coated and lecithin-coated furosemide.

Effect of Lecithin Coating on the Permeation of Furosemide through Calu-3 Cell Monolayers The penetration-enhancing effect of the lecithin coating was evaluated in an in vitro experimental system using Calu-3 cells as model respiratory epithelial cells. A suspension of un-coated or lecithin-coated furosemide in PBS was prepared and then immediately applied to the apical surface of the Calu-3 cell monolayers. Figure 3 shows the permeation profiles of

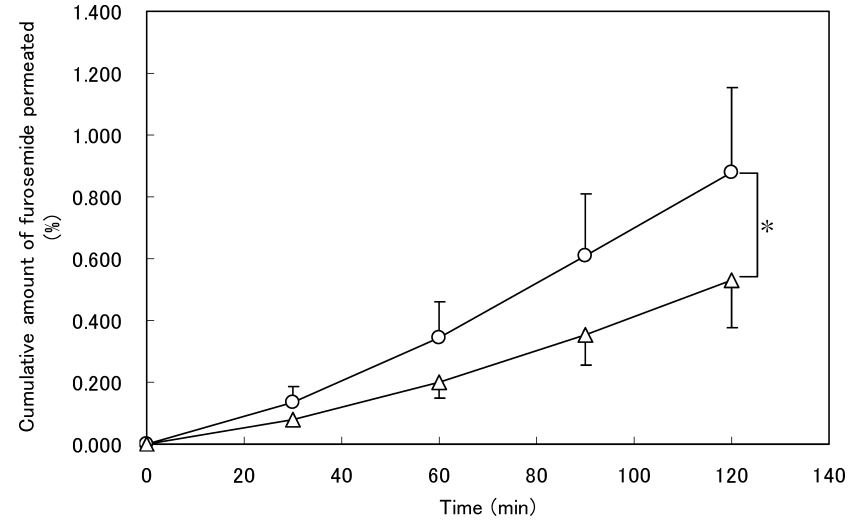

Fig. 3. Effect of Lecithin Coating on the Permeation of Furosemide through Calu-3 Cell Monolayers

Furosemide or lecithin-coated furosemide suspension (10 $\mathrm{mg}$ furosemide/ml PBS) was applied $(100 \mu \mathrm{l})$ to the apical side of Calu-3 cell monolayers $\left(0.33 \mathrm{~cm}^{2}\right) . \triangle$, furosemide; O, lecithin-coated furosemide. Each data set is the mean \pm S.D. $(n=6$, furosemide; $n=9$, lecithin-coated furosemide). $*$ Significant difference in unpaired Student's $t$-test $(p<0.05)$.

Table 3. Transepithelial Resistance of Calu-3 Cell Monolayers

\begin{tabular}{lccc}
\hline \hline & $\begin{array}{c}\text { Before } \\
\text { permeation } \\
\text { study }\left(\Omega \cdot \mathrm{cm}^{2}\right)\end{array}$ & $\begin{array}{c}\text { After } \\
\text { permeation } \\
\text { study }\left(\Omega \cdot \mathrm{cm}^{2}\right)\end{array}$ & $\begin{array}{c}\text { Reduction } \\
(\%)\end{array}$ \\
\hline Un-coated furosemide & $2766 \pm 365$ & $1468 \pm 467^{a)}$ & $45.0 \pm 17.0$ \\
Lecithin-coated furosemide & $2368 \pm 322$ & $932 \pm 234^{b)}$ & $60.6 \pm 8.2$
\end{tabular}

Each data set is the mean \pm S.D. $(n=6$ or 9$)$. a) Significant difference compared with values before permeation studies in a paired Student's $t$-test $(p<0.005)$. $b$ ) Significant difference compared with values before permeation studies in a paired Student's $t$-test $(p<0.0001)$.

furosemide through the Calu-3 cell monolayers. The cumulative amount of furosemide permeating from the lecithincoated furosemide over $2 \mathrm{~h}$ was significantly higher than that from un-coated furosemide and this was attributed to the penetration-enhancing effect of lecithin. The TER values were reduced significantly for both treatments in the $2 \mathrm{~h}$ permeation experiments (Table 3). Application of drug suspensions may have some effect on the monolayers cultured in air-interface conditions. Although there was no significant difference in the reduction between un-coated and lecithincoated furosemide suspensions, the reduction was higher for lecithin-coated suspensions and this could be related to the penetration-enhancing effect of lecithin.

\section{DISCUSSION}

In the present study, the effect of the lecithin coating on the pulmonary absorption of furosemide after application by an MDI containing HFA 227 was evaluated in rats. The plasma concentration of furosemide after application of lecithin-coated furosemide was higher than that after application of the un-coated form (Fig. 2). When the amount absorbed was calculated using the total body clearance in rats $(2.74 \mathrm{ml} / \mathrm{min} / \mathrm{kg}){ }^{25)}$ the value for the lecithin-coated furosemide was $0.707 \pm 0.107 \mathrm{mg}$ (mean \pm S.D.) which is equivalent to a bioavailability of $56.6 \%$ while the value for the un-coated furosemide was $0.218 \pm 0.070 \mathrm{mg}$, which is equivalent to a bioavailabilty of $17.5 \%$. In order to discover the reason why the un-coated furosemide exhibited a low 
bioavailability, the disposition of furosemide in lung $2 \mathrm{~min}$ after intratracheal administration was evaluated. The amount of uncoated furosemide in the lung was significantly lower than that of the lecithin-coated form and the adsorption of the uncoated form to the polyethylene tube was significantly higher than that of the lecithin-coated form (Table 2). These results could be related to differences in the physicochemical properties of the surface of the particles. Since phospholipids are major components of the pulmonary surfactant, the lecithin-coated furosemide might exhibit a higher affinity for the lung tissue. Although the amounts adsorbed to the polyethylene tube were significant, especially in the case of the un-coated furosemide, the reduction in the $A U C$ was not fully explained by the amounts adsorbed to the tube. Part of the furosemide might be scattered to the external air after administration using the MDI. Since the equipment for administration used in this study had not been optimized for rats, this should be taken into account when discussing the usefulness of lecithin coating.

Another important factor influencing the bioavailability could be first-pass metabolism in the lung. Since one of the roles of alveolar macrophages is to remove foreign materials, avoidance of phagocytosis by alveolar macrophages and enhanced dissolution in the alveolar fluid could improve the bioavailability of drug particles applied to the lung. ${ }^{26)}$ Surface coating of particles by phospholipids could be useful to reduce the uptake by alveolar macrophages. ${ }^{27,28)}$ Although the lecithin coating did not enhance the dissolution of furosemide (Fig. 1), the coating may contribute to the increased bioavailability via a reduction in the uptake by alveolar macrophages.

Since lecithin exhibits an enhancing effect on the mucosal absorption of some drugs, ${ }^{15,16)}$ the lecithin coating of furosemide could increase the absorption rate through the epithelial cell layer in the lung. Although the amount of furosemide in the lung $2 \mathrm{~min}$ after intratracheal administration of un-coated furosemide was similar to the amount absorbed calculated from the total body clearance, the amount of lecithin-coated furosemide was significantly lower $(p<$ 0.005 ) than the calculated amount absorbed (Table 2). This difference could be partly due to the rapid absorption of furosemide from the lecithin-coated form during the early phase. The permeation-enhancing effect of the lecithin coating was investigated using Calu-3 cell monolayers. The results obtained show that furosemide has a higher permeation rate from the lecithin-coated form (Fig. 3). The enhancing effect of the lecithin coating could also contribute to the high plasma concentration of furosemide in rats. There is a possibility that nano-particles coated with lecithin can be transported into capillaries via phagocytosis by alveolar epithelial cells. ${ }^{29}$ However, in the case of the lecithin-coated furosemide, enhanced permeation of dissolved furosemide could be the mechanism involved because of the minor contribution of nano-particles to the particle size distribution and the rapid dissolution of the particles. In the $2 \mathrm{~h}$ permeation studies, the reduction of TER by application of a suspension containing the lecithin-coated furosemide was about $60 \%$ (Table 3 ). Although the TER at $2 \mathrm{~h}$ was still high $\left(900 \Omega \cdot \mathrm{cm}^{2}\right),{ }^{18)}$ the relationship between TER and the effects on permeation-enhancement and tissue damage will careful consideration for the future development of MDIs containing lecithin-coated drugs.

In conclusion, the absorption-enhancing effects of lecithin coating on the pulmonary absorption of furosemide after application by an MDI containing HFA 227 were shown in rats. Some of them could be related to the efficient delivery of the furosemide particles to the lung. The penetration-enhancing effect of the lecithin coating on the permeation of furosemide was also shown in Calu-3 cell monolayers. The lecithincoated furosemide will be useful for formulation of MDIs. In the addition, the lecithin coating offers a new approach to developing MDIs for other drugs exhibiting low bioavailability.

\section{REFERENCES}

1) Smith I. J., J. Aerosol Med., 8, s19-s27 (1995).

2) Kontny M. J., Destefano G., Jager P. D., McNamara D. P., Turi J. S., Van Campen L., J. Aerosol Med., 4, 181-187 (1991).

3) Leach C. L., Aerosol Sci. Tech., 22, 328-334 (1995).

4) Steckel H., Wehle S., Int. J. Pharm., 284, 75-82 (2004).

5) Keller M., Int. J. Pharm., 186, 81-90 (1999).

6) Hickey A. J., Dalby R. N., Byron P. R., Int. J. Pharm., 42, 267-270 (1988).

7) Tansey I. P., Spray Technol. Marketing, July, 26-29 (1994).

8) Malik S., Washington C., Purewal T. S., Int. J. Pharm., 186, 63-69 (1999).

9) Saso Y., Kondo S., Seki T., Morimoto K., J. Drug Del. Sci. Tech., 14 135-140 (2004).

10) Tarara T. E., Hartman S., Gill H., Kennedy A. A., Weers J. G., Pharm. Res., 21, 1607-1614 (2004).

11) Dickinson P. A., Howells S. W., Kellaway I. W., J. Drug Target., 9, 295-302 (2001).

12) Steckel H., Thies J., Muller B. W., Int. J. Pharm., 152, 99-110 (1997).

13) Saso Y., Seki T., Chono S., Morimoto K., J. Drug Del. Sci. Tech., 16 147-150 (2006)

14) Byron P. R., Pharm. Res., 11, 580-584 (1994).

15) Kobayashi S., Kondo S., Juni K., Pharm. Res., 13, 80-83 (1996).

16) Mitra R., Pezron I., Li Y., Mitra A. K., Int. J. Pharm., 217, 25-31 (2001).

17) Cooney D., Kazantseva M., Hickey A. J., Altern. Lab. Anim., 32, $581-590$ (2004).

18) Forbes B., Ehrhardt C., Eur. J. Pharm. Biopharm., 60, 193-205 (2005).

19) Yang T., Mustafa F., Bai S., Ahsan F., Pharm. Res., 21, 2009-2016 (2004).

20) Fiegel J., Ehrhardt C., Schaefer U. F., Lehr C.-M., Hanes J., Pharm. Res., 20, 788-796 (2003).

21) Enna S. J., Schanker L. S., Am. J. Physiol., 222, 409-414 (1972).

22) Kobayashi S., Kondo S., Juni K., Pharm. Res., 11, 1239-1243 (1994).

23) Okumura K., Iwakawa S., Yoshida T., Seki T., Komada F., Int. J. Pharm., 88, 63-73 (1992).

24) Davies N. M., Feddah M. R., Int. J. Pharm., 255, 175-187 (2003).

25) Chen C., Scott D., Hanson E., Franco J., Berryman E., Volberg M., Liu X., Pharm. Res., 20, 31-37 (2003).

26) Jones B. G., Dickinson P. A., Gumbleton M., Kellaway I. W., J. Pharm Pharmacol., 54, 1065-1072 (2002).

27) Cook R. O., Pannu R. K., Kellaway I. W., J. Control. Release, 104, $79-90$ (2005).

28) Evora C., Soriano I., Rogers R. A., Schakesheff K. M., Hanes J., Langer R., J. Control. Release, 51, 143-152 (1998).

29) Kato T., Yashiro T., Murata Y., Herbert D. C., Oshikawa K., Bando M., Ohno S., Sugiyama Y., Cell Tissue Res., 311, 47-51 (2003). 